\title{
Research on Optimization and Application of University Student Development and Management Strategy Driven by Multidimensional Big Data
}

\author{
Zhimei Lv (iD) \\ Engineering Faculty of Economics, Henan Institute Economic and Trade, Zhengzhou, Henan 450018, China \\ Correspondence should be addressed to Zhimei Lv; lvzhimei@henetc.edu.cn
}

Received 17 December 2021; Accepted 17 January 2022; Published 8 February 2022

Academic Editor: Baiyuan Ding

Copyright (c) 2022 Zhimei Lv. This is an open access article distributed under the Creative Commons Attribution License, which permits unrestricted use, distribution, and reproduction in any medium, provided the original work is properly cited.

\begin{abstract}
The purpose of education is to enable students to develop fully, freely, comprehensively, and harmoniously. The development of college students is a social problem that must be focused on in higher education under the background of China's powerful human resources. It is an important subject that higher education must attach great importance to and solve to find out the way and method to solve and avoid the development of college students to help them face risks correctly, meet challenges, and grow healthily. Under the background in the era of big data, Internet and mobile intelligent terminal has great popularity in colleges and universities, especially in the digital library, the official platform construction, and is widely used in Internet multimedia technology in college classroom, although for college students and the teacher provides vast amounts of information data, exploring the college students' horizons, enriching the students' knowledge structure. But the explosive growth of data and information security threat to the development of college students management work still bring the severe test of this; education workers in colleges and universities should comply with the development of The Times, the big data organic blend in the current education system, and the specific practice of education, for modern education practice and college students' all-round development's age characteristic new development mode and effective way. In order to adapt to the new form of the development of The Times, the management of colleges and universities should keep pace with The Times, and integrate the concept of big data and advanced technology into the education management work, so as to realize the national deployment of the education system innovation development strategy, explore teaching rules, students' growth and development tasks, and other realistic needs of the times. In addition, making big data the most powerful internal driving force for educational development helps colleges and universities to realize the frontier, timeliness, interactivity, and individuation of educational management. Colleges and universities should actively apply the idea of big data, improve the data resource integration and use ability of the staff in the field of education management through diversified means, improve the management level in multiple dimensions, and promote the updating and upgrading of the management structure of higher education and teaching. By analyzing the background of big data era, this paper analyzes the challenges of college students' management in the era of big data and puts forward the strategies of college students' management in the era of big data, so as to improve the quality and efficiency of college students' management.
\end{abstract}

\section{Introduction}

'College students' development' is a relatively broad concept. At present, the academic circles at home and abroad have not formed a consensus on its meaning. Overall, due to focus on topics or scholars in the emphasis of study on the definition of the elements or dimensions "college students" development in scattered, in summary mainly two levels, namely, the development of cognitive ability (IQ) and the development of cognitive ability (quotient and), are receiving higher education. College students' knowledge, ability, social relations, quality, and personality can be developed in an all-round way. The development of college students cannot be separated from specific historical conditions, and the theme of the era often becomes the theme of college students' development [1-3]. College students' 
development refers to the students at the university of this particular time and space scope is not only the development of specific tasks to complete the university stage, in order to achieve the basic curriculum standards of graduating from college; what is more important to within limited time and space form can make college students after graduation life still can let themselves get comprehensive and ability of sustainable development $[4,5]$. In other words, the development of college students is an internal and gradual growth process of college students with development tasks as the goal orientation.

To accurately grasp the real situation development is the premise and the study of college students' development. Environment is the external influencing factor of college students' development, and the change of environment often leads to profound changes in college students' behavior and lifestyle. Scholars mainly start from the social environment and educational environment of college students' development, through studying the change of the environment and its impact on college students' development, discuss how college students choose the best, and remove the bad in the environmental transformation to promote their own development [6]. The decrease of the social status of the students, the ideological and moral quality of ordinary questioned, learning stress, the growth of employment prospects uncertain, psychological problems and psychological barriers, mental disease frequently occurred, etc., are the outline of the growth of contemporary college students; this group development needs to cause the social, especially the higher education.

There is no doubt that higher and newer requirements are put forward for the education quality of college students. The traditional teaching mode is relatively rigid, education system is lack of necessary, consistent with the facts, and the timeliness of data information support makes the current college education practice in the ideological content and scientific shortcomings in one way or the other difficult to be fundamental for college students to provide an influential modern education content of keeping the pace [7]. Therefore, college education should be inclined or give consideration to digitalization and networking to meet the needs of the development. From the macro level, relying on big data can make educators timely obtain the real dynamic information related to college students' thoughts and behaviors, and can analyze and track it and predict its prospects, so that the importance of data information to know the behavior dynamics of college students is selfevident; from the micro level, according to the big data to analyze the ideological situation, behavior habits, and values of college students, explore their internal roots and influencing factors, so as to develop practical and highly targeted education programs. Therefore, through the analysis of the collected, screening, and college students' information data can be found in time and accurate prediction for the college students during the period of the thought and behavior development and can also find their aptitude or the circumstances of education method; education under the big data is more scientific, precision, accuracy, effectiveness and flexibility [8].
Big data provide massive or all data, which are more conducive to quantitative analysis and precise guidance; it reflects the general direction of the dynamic development of things, which is more conducive to grasp and control on the macro level [9]. It gives the correlation between things, which is more conducive to decision-making and targeted problem-solving. Therefore, big data are of more and more attention and aroused people's attention, both academic, business, enterprise, and government; almost all industries or different use big data acquisition, collection of the platform selection, and quantitative analysis of huge amounts of information data, greatly improving the work efficiency, and promote the rapid development.

Many universities in the teaching, learning, research, general services, library, and other business departments have to establish and perfect the relevant data of information system and accumulated a lot of college students information data, such as the recruitment of students employment, course selection, test scores, poor students archives, consumer spending, library access records, etc., and all of these data contain a multitude of complicated correlations, from consumer spending to the amount of poverty subsidies to course choice to grades [10]. As an organic whole, the data and information resources of various departments should be reasonably shared or seamlessly connected, but the fact is not so. First, there are problems such as weak connection, small horizontal data flow, and insufficient information resource integration among various business departments. Second, the data information standards of each business system information data platform are different, with various formats and poor accuracy, making it difficult to share resources among databases. In a word, the phenomenon of "information data isolation" among various departments in most colleges and universities is quite serious, which has become the bottleneck problem that information data resources of various departments in schools cannot be shared.

\section{Student Development and Management Strategies}

As globalization penetrates from the economic field to the educational field, the development of college students is confronted with the value conflicts of tradition and openness, eastern culture and western culture, and social interests and personal interests. At the same time, most families in China lack rational thinking about independent education for their children, and the educational management of colleges and universities is also largely deficient in this aspect, which causes a series of social problems. Universities should optimize the content of educational management. To cultivate the students' independent ability and self-education ability in important position, cultivate their good psychological quality, improve their social adaptation ability and the ability to withstand setbacks, to strengthen their emotional education and moral education, promote comprehensive coordinated development, and cultivate talents with high comprehensive quality and spiritual character. The development process of individual social attribute has regularity, objectivity, universality, and particularity 
[11-13]. A comprehensive survey of the basic situation in colleges and universities shows that educators do not pay enough attention to it. First, there is a general lack of overall and overall top-level design and the lack of guiding specific educational practice with the concept of big data. Second, many higher education workers do not know much about the concept of big data, let alone apply it to educational practice. Third, the lack of grasp of the character and behavior dynamics of college students unable to actively use big data to collect relevant information data and naturally unable to find a more willing form of communication; the traditional teaching habit of reading from a book is hard to recover [14].

From the perspective of college student management, students are the "absolute" subject and the primary goal and fundamental starting point of education. College students mainly refer to the cultivation of students with excellent ideological and moral quality, reasonable knowledge structure, excellent ability and quality, profound scientific and humanistic quality, positive personality psychology, healthy body, and appropriate degree of socialization in the development process and finally achieve comprehensive development. Teachers should strengthen the political theory on "thought" learning, unswervingly adhere to the student's main body status, give the students more "humanistic care," close to the student's learning, life, and thoughts, focus on the students' inner feelings and reality need, understand the autonomy and initiative of students, really respect students, concern for students, to cultivate students, take the overall development of students as the fundamental, value realization as the goal, and do "everything for students." The action should strengthen their own vocational skills training, at the same time adhere to the subject status of students unshaken, and change the past cramming, exam-oriented, didactic teaching way, to achieve personalized, humanized, humane teaching [15]. The management of college students must face all students and be committed to the comprehensive development of all students. College teachers must remove colored glasses and respect, love, and care for every student. In terms of role positioning, teachers must realize the importance of equality and reposition themselves as guides and cooperators. At the same time, students should increase their sense of identity, timely eliminate their inner "subordinate" understanding, good at expression, and the courage to act. In the system construction, we should strengthen the participation of students, optimize the structure of student organizations, expand the function of student organizations, respect and protect the rights of students through the system construction, and wake up the sense of ownership of students. Process diagram of knowledge discovery is shown in Figure 1.

The growth and development of college students is a complex system development process, which is not only the physical nature of individual growth and maturity, but also the construction of complex social relations. Since entering the $21^{\text {st }}$ century, big data can increasingly reflect the specific laws of the development of things. With the gradual maturity of data mining technology, compared with personal experience, decisions made based on big data are more objective and effective. On college students' education policy formulation, the traditional meaning of the research type and decision questioned by many, but in the new century is based on the context of the dynamic attention by the people, is a decentralized, constantly updated, multidimensional, can store, classification and analysis of different regions and education subject and the object of information data $[16,17]$. Large-scale educational data can also be obtained from the websites of the Ministry of Education and local education administrative departments and college students' education. The basic data obtained through these means can be used to formulate sound education policies. Thus, for college students' education, data collection will make education more convincing and credible. Big data can make educational activities achieve maximum effect and adjust educational methods and means at any time. Big data are real time, dynamic, and forward-looking. In order to provide corresponding feedback and guidance, with the deepening of learning activities, students' learning database and background information system, past assessment, and learning data will be constantly updated [18].

In the context of big data, the teaching data can be subdivided to an incredible extent through computer intelligent teaching and evaluation system, and the massive data generated by students inside and outside the classroom can be mined to record the data generated by students in the classroom. Therefore, big data analysis can fully and truly reflect the quality of education, making education personalized, diversified, and accurate. From the aspect of students, we can dig out their education level, cultural habits, and so on; at the national level, data such as education input and relevant curriculum can be collected through tests and questionnaires. For example, it can understand the grasp of classroom knowledge and the accuracy of notes, the notes learned in class [19]. It can understand students' learning rules and predict students' learning behavior. And in order to make students present as holographic data, big data can pay attention to students' health data, social communication data, etc., can collect multidimensional data about students' learning, so that educational institutions and educators pay attention to what students are good at, and guide students' sustainable development.

By tracking students' online learning trajectory and analyzing each forum post that students read, we can find the best teaching methods and determine which forum posts are most suitable for students to read. For example, when students watch teaching videos, analyze which section of content can be directly skipped, which section can be replayed, and so on. The analysis of these massive data can fully give college students with autonomy and choice in learning and can completely change the current backward teaching methods. Online education providers can formulate the following learning courses, progress, and difficulty according to students' learning conditions, so as to avoid the situation of losing one to the other. For example, due to different regions and educational levels, students' Chinese foundation is too different, which leads to the poor teaching quality of college Chinese in public 


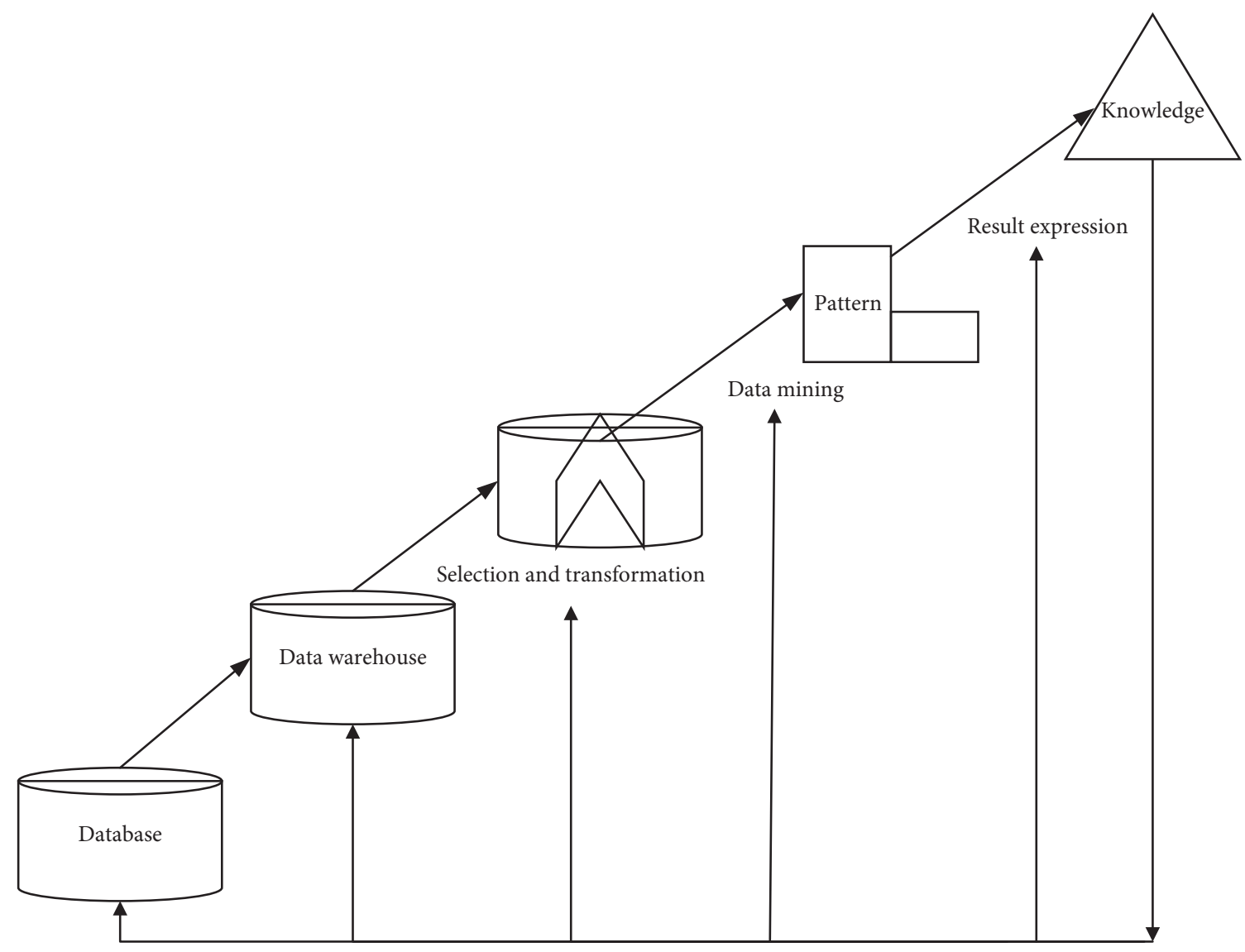

Figure 1: Process diagram of knowledge discovery.

courses. The results obtained through the analysis of students' learning situation through big data can maximize the classroom effect, but also enable teachers to adjust the content [20].

In short, people are still accustomed to the traditional education mode of light driving, and the awareness of big data utilization needs to be improved. The sample size of big data is large and complicated, and the structure is diverse, and the distribution is extremely extensive. The information data generated by college students every day in the library, classroom, dormitory, and so on are enormous and exist in the form of chaotic fragments. The collection and storage of big data is the primary problem that people are faced with. Big data types and sources of information are widely multifarious, generate and update frequency is high, how to carry on the scientific and reasonable collection, storage, and thus have a complete information data, how to select the timeliness of information data sorting, finally get scientific analysis results, and it is also higher educators are facing a big problem. Renderings of two algorithms are shown in Figure 2.

\section{Multidimensional Big Data-Driven Approach}

The first category is predicting the unknown. The second category is automatic partitioning of vast amounts of unlabeled data and automatic clustering of similar things.

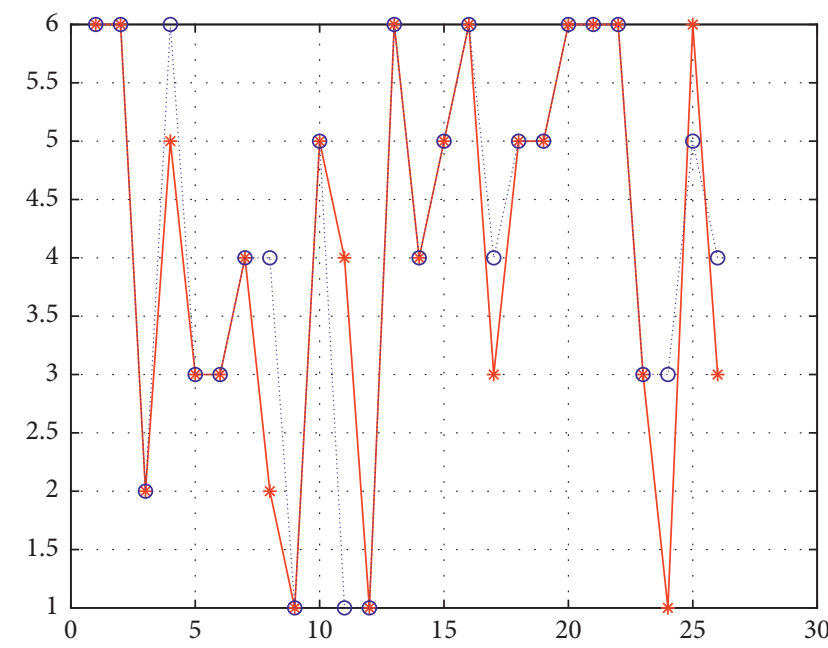

FIgURe 2: Renderings of two algorithms.

Classification is mainly the classification of new things. At present, there are many very successful classifiers, such as decision tree, naive Bayes, artificial neural network, support vector machine, etc. All of these algorithms can be classified, and some algorithms can build good structural models, which can explain the whole data set well [21, 22]. For example, psychology uses clustering to study the causes of depression, biology uses automatic classification of 
organisms, and information retrieval uses clustering to group similar web pages together. The following uses $\mathrm{C} 4.5$ as an example to describe the process of building a decision tree.

The calculation formula of information entropy of each node is as follows:

$$
\begin{gathered}
\text { gain }=\operatorname{info}(T)-\sum_{i=1}^{s} \frac{\left|T_{i}\right|}{T} \times \operatorname{info}\left(T_{i}\right), \\
\operatorname{info}(T)=-\sum_{j=1}^{N \text { Class }} \frac{\operatorname{freq}\left(C_{j}, T\right)}{|T|} \times \log _{2}\left(\frac{\operatorname{freq}\left(C_{j}, T\right)}{|T|}\right) .
\end{gathered}
$$

where, $T$ is the data set owned by the node and freq $\left(C_{i}, T\right)$ is the frequency of each $i \in[1, N$ class $]$.

The calculation principle of local consistency is relatively simple, mainly using the Kendal Concorde coefficient, and the specific calculation formula is as follows:

$$
W=\frac{12 \sum\left(R_{i}\right)^{2}-n(\bar{R})^{2}}{\mathrm{~K}^{2}\left(n^{3}-n\right)}
$$

where $\mathrm{K}$ is the number of evaluation, $n$ is the number of individuals, $R_{i}$ is the sum of the rank of the $i$-th individual, and $\bar{R}$ is the average value of all individuals.

The calculation formula of single-sample statistics is as follows:

$$
t=\frac{\bar{X}-\mu}{\delta_{x} / \sqrt{n-1}}
$$

where $t$ is the statistics of the sample mean and the population mean, $\bar{X}$ is the sample mean, $\mu$ is the population mean, $\delta_{x}$ is the standard deviation of the sample, and $n$ is the number of samples.

The calculation of the statistics of the hypothesis of the single-body sample is as follows:

$$
t=\frac{\bar{X}_{1}-\bar{X}_{2}}{\sqrt{\left(n_{1}-1\right) S_{1}^{2}+\left(n_{2}-1\right) S_{2}^{2} / n_{1}+n_{2}-2\left(1 / n_{1}-1 / n_{2}\right)}}
$$

where $\bar{X}_{1}$ and $\bar{X}_{2}$ are the mean of the sample, $S_{1}^{2}$ and $S_{2}^{2}$ are the mean of the sample, and $n_{1}$ and $n_{2}$ are the number of samples.

Set two random sequences $X$ and $Y$, Pearson correlation coefficient between the two sequences is $r$, and then

$$
r=\frac{\operatorname{cov}(X, Y)}{\sqrt{\sigma_{x}^{2}} \sqrt{\sigma_{y}^{2}}}=\frac{\sum_{i=1}^{n}\left(x_{i}-\bar{x}\right)\left(y_{i}-\bar{y}\right)}{\sqrt{\sum_{i=1}^{n}\left(x_{i}-\bar{x}\right)^{2}\left(y_{i}-\bar{y}\right)^{2}}}
$$

where $\sigma_{x}^{2}$ and $\sigma_{y}^{2}$ is the variance of random sequence $X$ and $Y$, $\operatorname{cov}(X, Y)$ is the covariance of random sequence $X$ and $Y, \bar{x}$ and $\bar{y}$ are the mean value of variables, and $n$ is the length of sequence $X$ and $Y$.

In order to ensure the accuracy of the results, this paper uses two evaluation indexes, mean absolute error, and root mean square error, to evaluate the optimization effect of the model. The specific calculation formulas are as follows:

$$
\begin{aligned}
\text { MAE } & =\frac{1}{s} \sum_{i=1}^{s}\left|\widehat{y}_{i}-y_{i}\right|, \\
\text { RMSE } & =\sqrt{\frac{1}{s} \sum_{i=1}^{s}\left[\widehat{y}_{i}-y_{i}\right]^{2},}
\end{aligned}
$$

where $y_{i}$ is the actual value of the variable, $\hat{y}_{i}$ is the predicted value of the variable, and $s$ is the number of predicted samples.

There are many ways to normalize data, but one common goal is to make data dimensionless between data. This paper summarizes the following data standardization methods based on several literature.

Range transformation formula of cost index is as follows:

$$
y_{i j}=\frac{x_{i j}-\min _{i \in\{1,2, \ldots, n\}} x_{i j}}{\max _{i \in\{1,2, \ldots, n\}} x_{i j}-\min x_{i j}},
$$

where $x_{i j}$ is data sample.

The transformation formula of fixed indicators is as follows:

$$
y_{i j}= \begin{cases}\frac{\min \left|x_{i j}-a_{j}\right|}{\left|x_{i j}-a_{j}\right|}, & x_{i j} \neq a_{j}, \\ 1, & x_{i j}=a_{j},\end{cases}
$$

where $a_{j}$ is the optimal stable value of the $j$-th indicator $f_{j}$. Interval transformation formula is as follows:

$$
\begin{aligned}
& 1-\frac{q_{1}^{j}-x_{i j}}{\max \left\{q_{1}^{j}-\min _{i \in\{1,2, \cdots, n\}} x_{i \in\{1,2, \cdots, n\}} \max _{i j}-q_{2}^{j}\right\}}, \quad x_{i j}<q_{1}^{j}, \\
& y_{i j}= \begin{cases}1, & x_{i j} \in\left[q_{1}^{j}, q_{2}^{j}\right], \\
1-\frac{x_{i j}-q_{1}^{j}}{\max \left\{q_{1}^{j}-\min _{i \in\{1,2, \cdots, n\}} x_{i \in\{1,2, \cdots, n\}} \max _{i j}-q_{2}^{j}\right\}}, & x_{i j}>q_{2}^{j},\end{cases}
\end{aligned}
$$

where $\left[q_{1}^{j}, q_{2}^{j}\right]$ is the optimal stability interval of $f_{j}$.

And based on the current social development, focus on shaping the concept of big data, gradually improve and optimize the campus information management platform, create a first-class professional data faculty, and accelerate the implementation of campus big data innovation management work at multiple levels for college students to create the campus order conducive to their deep learning [23]. Colleges and universities can build a convenient 
platform and innovate the mode for education management through big data, which can also help universities achieve the goal of information-based supervision and facilitate the construction of campus internal information management. Colleges will create an orderly, harmonious, and humanized management atmosphere in the process of properly planning and building the educational management structure. In order to cater to the trend of social development and meet the demands of current educational management, universities should focus on the integration into educational management and carry out educational management upgrading centering on information innovation.

3.1. Shaping "Big Data View." In order to ensure the routinization and systematization of educational management, school leaders should lead in-service teachers to shape correct "big data view" and strengthen the effectiveness of educational management. First, when implementing educational management, the school should take data as the core basis, establish the management concept of "handling affairs with data and managing with data," and speed up the transformation of information educational management. Collect, integrate, analyze, and distinguish the existing educational resources in the campus, the teachers and staff groups, the number and scale of students, the latest educational requirements, the basis of education management, and other aspects of data, strengthen the management of campus data resources, and ensure that it matches with the teaching management, to ensure the effectiveness of management; Second, when building the big data platform for education management, the school should organize education managers to hold relevant meetings on the confidentiality of data resources to emphasize the risk of information resource disclosure, so as to maintain the stability and security of the operation of the data platform. Three inside the campus is big data concept expansion training activities; leaders at all levels and teacher encouraged to actively participate, by learning the latest management idea, instead of the old, do not cut time management concept, forming large data thinking, actively explore the education management channel, increase management of modern elements, and ensure that the new educational management concept meets students' current psychological expectations [24].

3.2. Information Platform Construction. As the core of multidirectional application of university data resources, the construction of university's own information platform is extremely important. At present, local colleges and universities in China often encounter many obstacles in the establishment of information platform, such as lack of capital and human resources, resulting in the platform's single function, poor experience, lack of personalized services, and other problems. In order to completely solve the above problems and complete the task of constructing big data platform, colleges and universities can adopt the following methods to solve them: first, integrate data. The detailed information data of the campus are analyzed in a centralized manner, and the data with distinctive characteristics are analyzed to explore its causes and unified input of sorted data resources into the data platform, reflecting the characteristics of open platform; second, pay attention to the financial capital reserve data. Carry out a rigorously situation of colleges and universities, and make a detailed budget for the funds used in platform construction. If there is still surplus funds after the platform is perfected, innovation sections can be continuously added to improve the comprehensiveness of the platform when it is put into use in the future. If the cost is insufficient, colleges and universities can seek investment help from enterprises. The university can determine the quality of its products by itself and obtain platform investment through internal publicity on campus [25].

3.3. Data Team Construction. In-service teachers are the key group in the educational management. In order to make their comprehensive ability and quality match the cuttingedge information education management, universities should pay attention to the professional training of teachers. According to their job functions, college teachers can be divided into two categories: one is the teachers who participate, and the other is the administrative teachers who carry out management work. First, cultivate the big data concept of full-time educational management teachers. The school should be regularly invited big data information industry pundits, campus at all levels of line management experts and scholars such as teachers, information platform maintenance upgrade, big data shaping skills such as content, information platform launched special training lectures, strengthen management teachers' ability to use big data technology, and guarantee the education management effect. Second, encourage teachers management in the free time to learn the advanced education management through multiple channels, information platform, big data technology, and related theory knowledge, such as the Internet, radio and television, books, newspapers and magazines, etc., make its armed mind, and strengthen the big data effectiveness of education and teaching management, to ensure smooth implementation of education management work, and finally, the landing of collaborative innovation [26].

3.4. Formulating a Management System. In this regard, during the formal planning and construction of the system, the school should highlight the following points to enhance innovation efficiency: first, the collection system. Much data will be generated in the daily management, and a large data storage database will be established over time. In the absence of specific detailed management, data resources can not be properly utilized, but also cause problems such as data accumulation disorder and loss [27].

The overall normative teaching standards, teaching language, teaching methods, educational concepts, and other aspects are set as the content of data collection, and unified standards of data entry are set to avoid the risk of invalid data. In this way, teachers and students can timely 
harvest the real-time refinement of teaching and learning and carry out targeted optimization and improvement on the hidden problems, so as to strengthen the effectiveness of teaching and management [28]. The second is the application system. To improve the construction of big data platform as the focus, colleges and universities need to add many applications one by one, such as capital and finance, campus security, resource allocation, teaching management, teacher-student interaction, teaching support, events, major decisions, and other core sections, to avoid the problem of single data platform.

To sum up, integrating big data into the field of education management can become a basic strategy in the future education system innovation. Based on the current social development, focus on shaping the concept of big data, gradually improve and optimize the campus information management platform, create a first-class professional data faculty, and accelerate the implementation of campus big data innovation management work at multiple levels [29]. For college students to create the campus order conducive to their deep learning, build a solid foundation for their longterm development, for the country to cultivate a large-scale, higher quality of college students [26]. Data table structure diagram is shown in Figure 3.

\section{Analysis and Discussion of Calculation Results}

At present, the idea of humanistic quality education in universities has become the theme of education and teaching. Under the guidance of this concept, to promote the quality development of college students requires that the education and management of the university should be constantly innovative, in the work to be targeted, not only to encourage outstanding on the basis of qualified, standard, but also to develop personality on the basis of standard requirements. The construction of practical guidance system from campus to real life, closely combined with social reality and the characteristics of college students' development, combined with university education and students' development ideal, to help college students set specific tasks in each stage. Second, in the process of practice, college students' development plan is established on the basis of the practice of the comprehensive evaluation system, the learning attitude and conduct performance, social practice, and so on into the appraisal scope, in integrating theory with practice, comprehensive evaluation, help students further understanding society, self-understanding, grasp myself, constantly updated knowledge and ability structure, and strive to achieve unity of knowledge and action to achieve optimal development. Quality measures under different parameters are shown in Figure 4.

Scatter plots with different parameters are shown in Figure 5. As can be seen from Figure 4, compared with the mean score of 3.49 , the mean score of 3.65 , and the mean score of expectation is the highest, which indicates that as follows: first, at present, college students in Y University have a strong desire to and they are eager to have the right to participate in school management. Second, college students

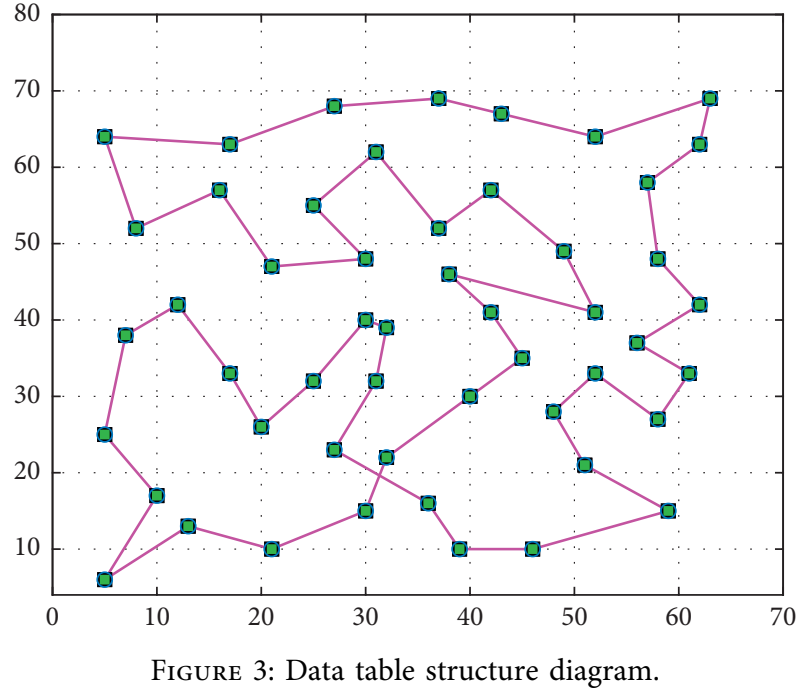

have a high understanding of their own behavior ability and believe that they have certain management ability and can exercise the right to participate in school management. The reason for this result may be that serving as a student cadre is an important means to train college students to effectively exercise their right to participate in school management. By serving as student cadres, students can exercise their own behavior ability related to school management, so that they can exercise the right to participate in school management given by law more effectively.

Cloud image of clustering results is shown in Figure 6. It can be seen from Figure 5 that at present, college students in Y University are mainly involved in teaching management and student management, while students are less involved in logistics management and administrative management. The proportion of college students choosing not to participate is relatively high in administrative management and logistics management, especially in administrative management matters. For example, $78.7 \%$ of college students choose not to participate in financial supervision activities, and $74.9 \%$ choose not to participate in institutional setting and personnel management reform. In terms of student management, only $10.4 \%$ of students do not participate in the democratic evaluation of the election of class and community leaders, and only $8.3 \%$ of the expenses such as class expenses form a sharp contrast. It can be seen that the overall situation of Y University students is better in terms of teaching management and student management than in administrative management and logistics management. In teaching management and student management, student knowledge, to present an opinion, participation in supervision and participation in decision-making are relatively high, the proportion of the students can not only be in the process of participating in details and provide opinions and suggestions, and in the administrative and logistics management students to participate in the activities of school management is more aware, but lack of voice, supervision, and decision-making power.

The class characteristic curve is shown in Figure 7. The data analysis of this study shows that there is not a simple 

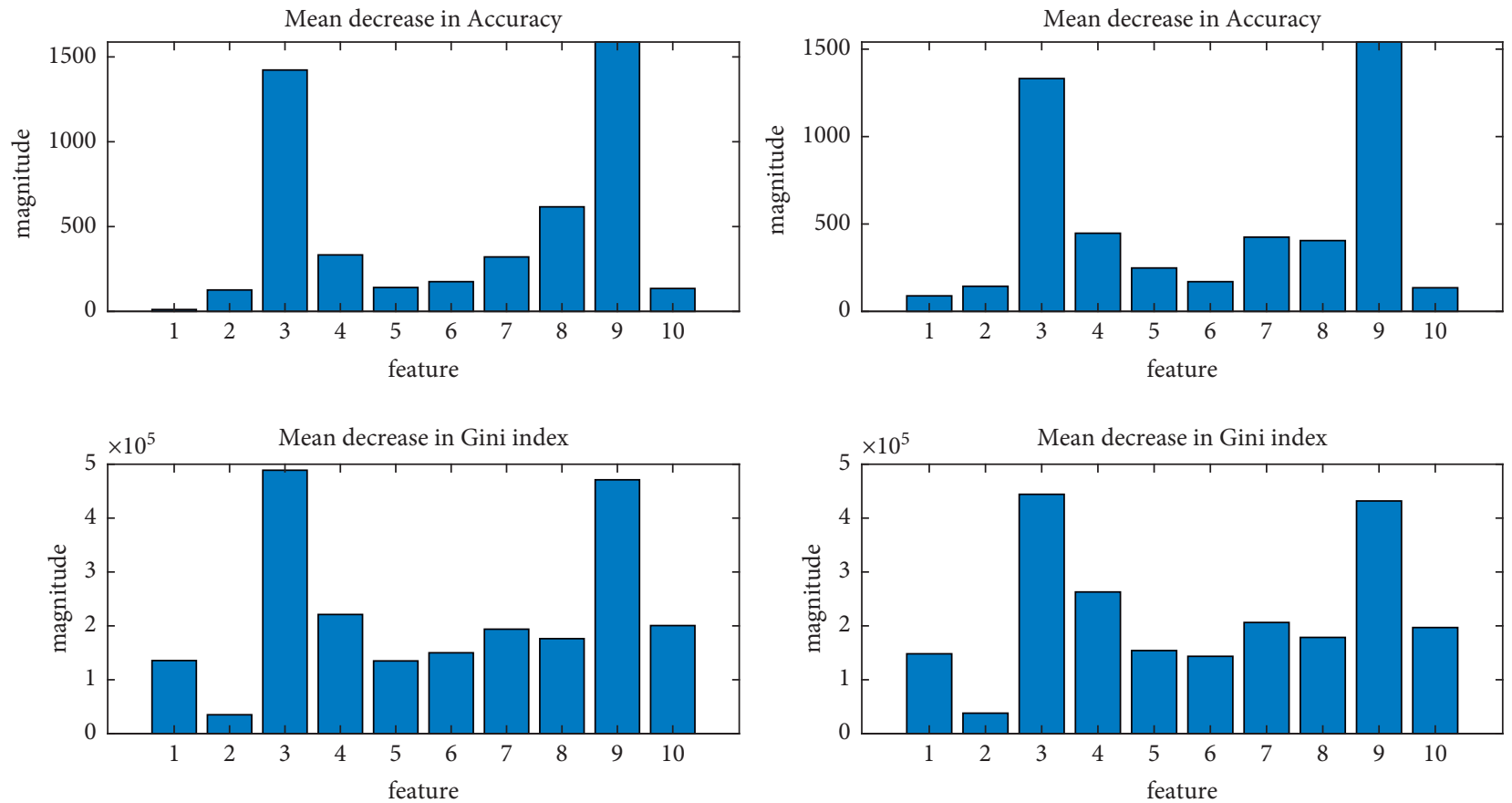

FIgURE 4: Quality measures under different parameters.
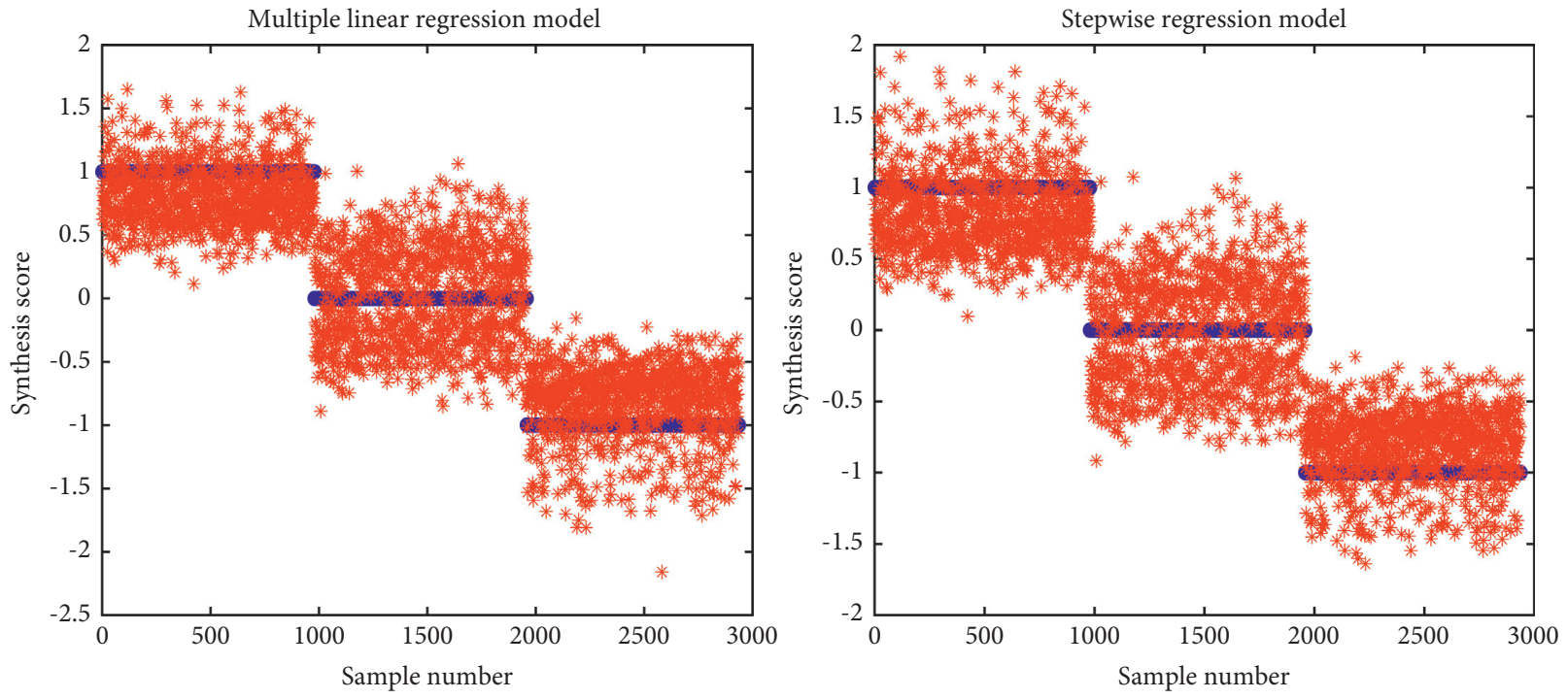

FIGURE 5: Scatter plots with different parameters. (a) Multiple linear regression model. (b) Stepwise regression model.

linear relationship between the cognitive formation path of data literacy individuals, the formation path mechanism of auxiliary skills, and the formation path mechanism of core skills. The influence of the three is mutual, and the formation path mechanism of auxiliary skills has the most significant effect. Therefore, the education of individual cognition, auxiliary skills, and core skills of data literacy should not be independent of each other, and the interaction of the three should be strengthened in the course setting so as to promote the formation of individual cognition, auxiliary skills, and core skills of data literacy to influence and promote each other. And the auxiliary skill formation path mechanism on individual cognitive data path mechanisms and core skills greatly influenced by the mechanism of forming path, therefore, in the curriculum should appropriately increase the proportion of secondary skills education courses and strengthen the education of the auxiliary skill curriculum and data quality personal interaction of cognitive and core skills course. In addition, different teaching practice contents have different influences on individual cognition, auxiliary skills, and core skills of data literacy, so different emphasis should be put on corresponding curriculum setting.

With the unique characteristics of big data technology, information will be continuously pushed according to the 

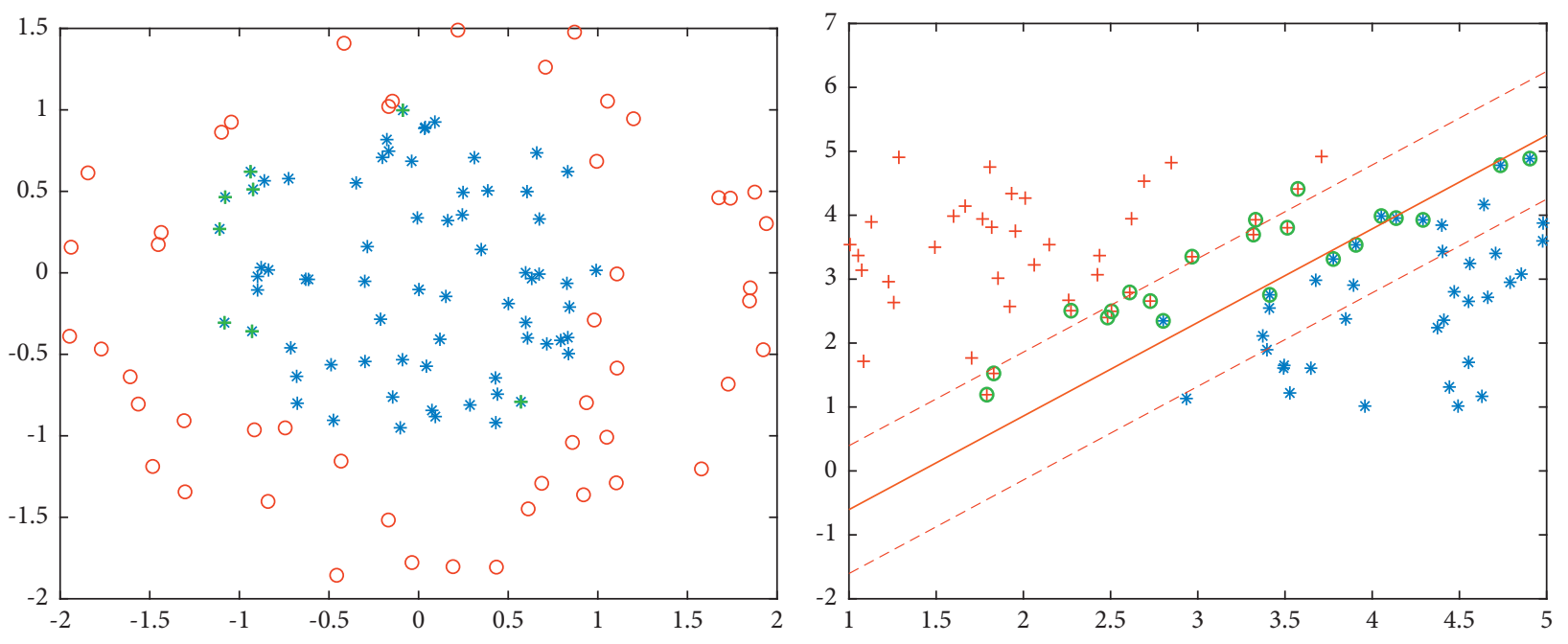

FigURE 6: Cloud image of clustering results.

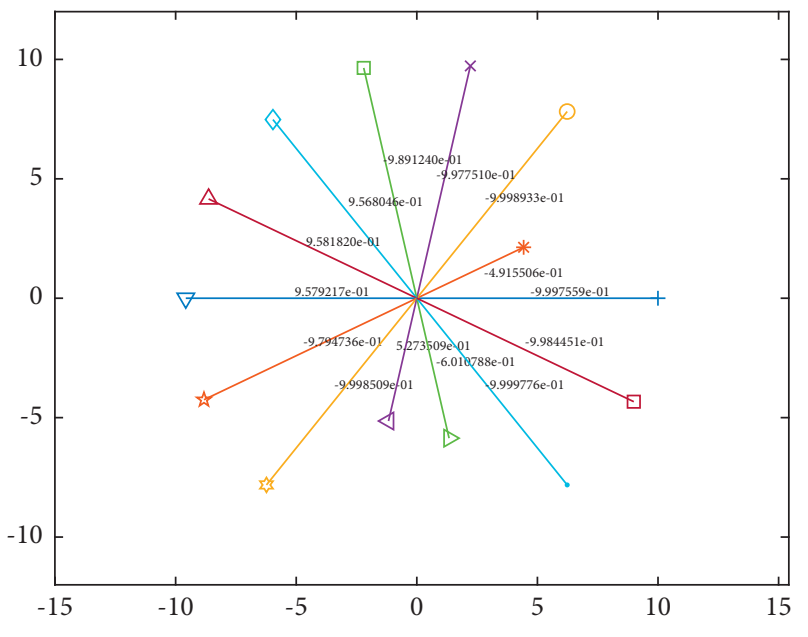

Figure 7: Class characteristic curve.
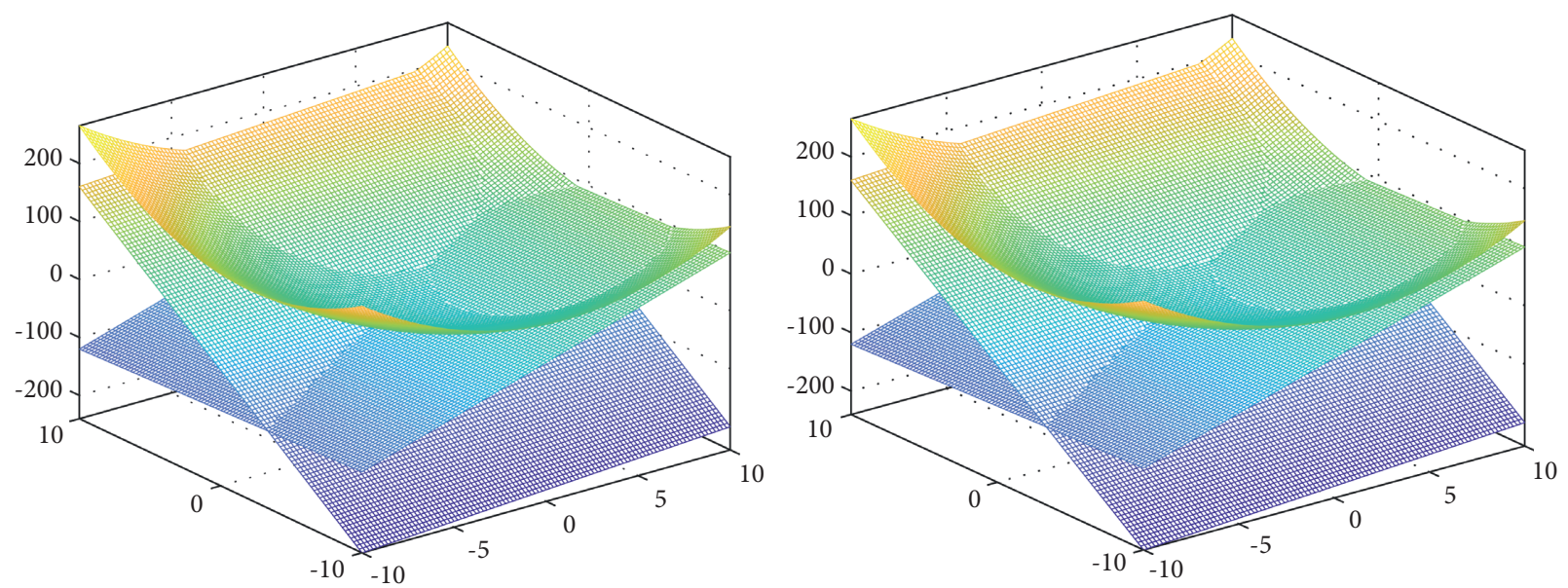

Figure 8: Distribution of eigenvalues of the observation matrix. 

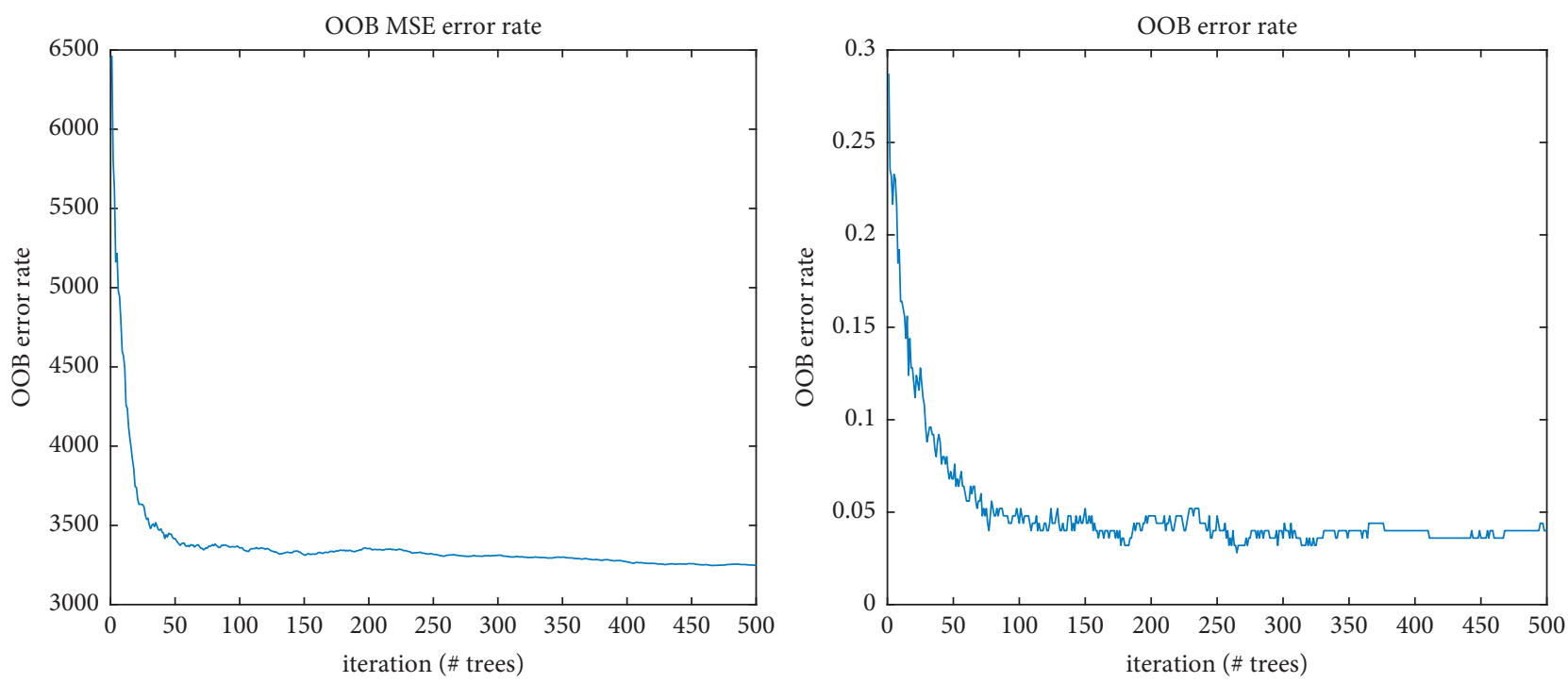

FIgURE 9: Information content and standard error distribution. (a) OOB MSE error rate. (b) OOB error rate.

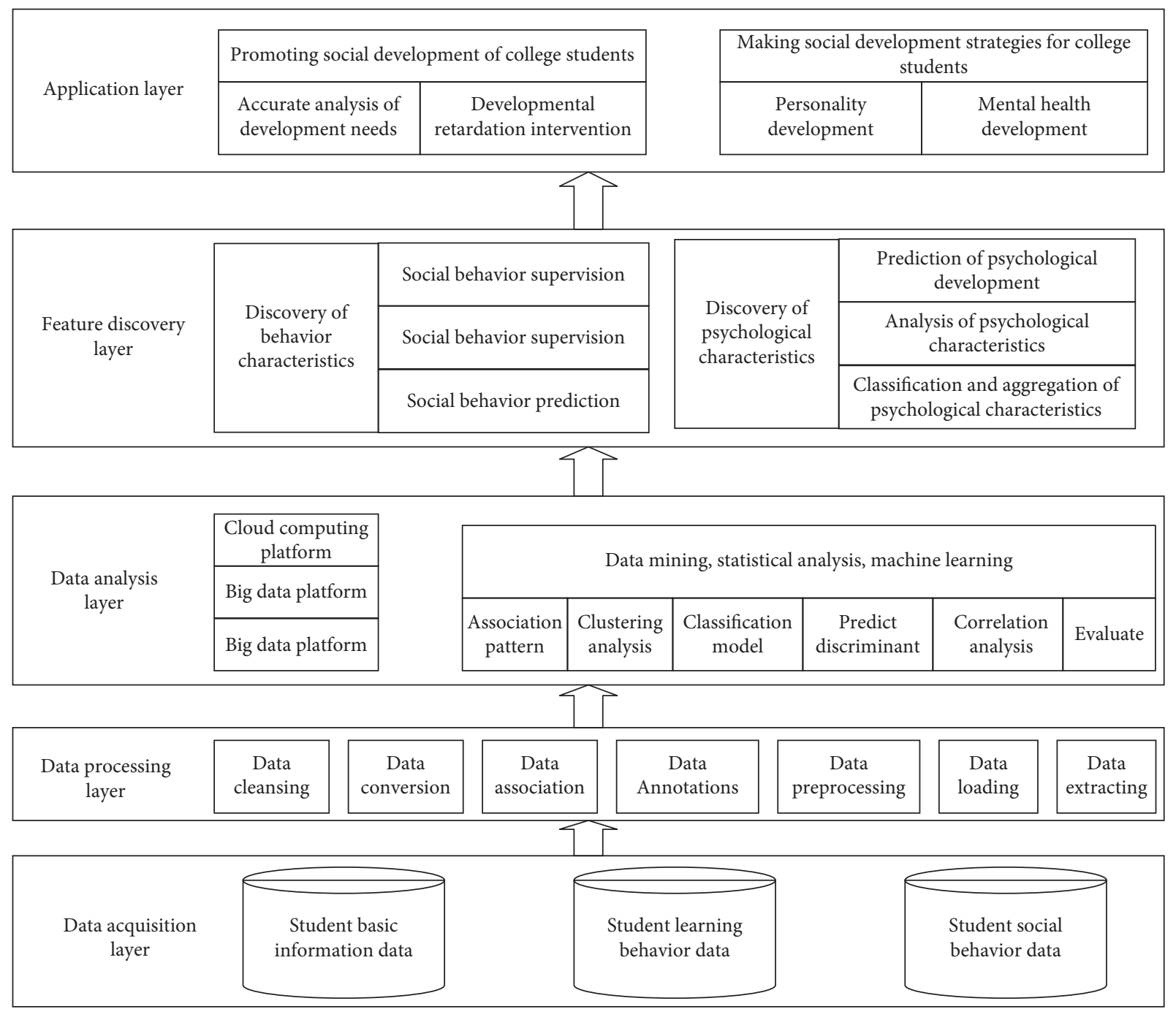

Figure 10: College student development model driven by multidimensional big data. 
public's interest points. First is the promotion of "participatory" teaching methods in teaching. This teaching method is characterized by question-based teaching and open content, with no standard answers to questions and few or no assignments and papers, which can give students enough time and space to think freely. Use network technology and computer technology to collect relevant information to answer questions, through the process of answering questions to complete the learning process. As information, identify the key to assimilate, process, and produce their opinions, and transfer their ideas to others. In this process, students not only master the ability to answer various questions with the help of the Internet but also finally learn the knowledge related to "questions." For different students, basic and comprehensive research promotion and three levels of learning and training and teaching, according to the characteristics of students to establish appropriate training objectives, design and formulate strict student learning plans, as far as possible to get good development. Distribution of eigenvalues of the observation matrix is shown in Figure 8.

At present, most universities implement the credit system, which is the management mode formed in the era of planned economy, with insufficient flexibility, too strong rigidity, and too much common binding force. In today's big data environment, we advocate a more personalized model of student management. The teacher management system takes the student as the center, the student as the leading, and the teacher as the auxiliary and establishes the student service center. The specific operations are as follows: first, the establishment of psychological consultation, first aid, work research, learning guidance mechanism, and the establishment of the corresponding community management department; second, based on student dormitories, classes are cancelled and 8-15 students and teachers form a whole. Third, graduate students or senior outstanding students to help manage students, to provide guidance for students. This management mode can realize students' self-education, selfmanagement, and self-service. Information content and standard error distribution is shown in Figure 9. The college student development model driven by multidimensional big data is shown in Figure 10.

\section{Conclusion}

Big data have been widely used in many industries and play an important role in promoting the development of human society in the new era. Admittedly, big data have not been widely applied to some extent in the educational practice of colleges and universities. Therefore, the workers on the front of college education must have firm confidence in reform, overcome all difficulties and obstacles, and make solid efforts to do big data homework. We must attach importance to improving resource allocation and optimizing data information technology management platform. Enhance the data awareness of teachers and students and improve the efficiency of data processing. Construct the authority organization and maintain the authority of university management work. Establish early warning mechanism, ensure the data security of teachers and students, and optimize and update the education management plan according to the feedback results of big data; ensure that the management of college students can keep pace with the development of the times, efficiency, and orderly direction. To this end, the paper proposes the following multidimensional big data-driven development and management strategies for college students:

(1) Improve resource allocation and optimize technology platform. The function of big data technology depends on the construction of Internet information technology to a great extent. Universities should clear the importance of big data information management, attach great importance to improve the allocation of resources, increase the investment of the construction of information platform, complete the necessary hardware and software facilities construction, optimizing the management information technology platform, efficient use of the popularity of the Internet, hyperlink information extension function, and mode of online education and the database platform sharing, and to ensure the standard input of personal data information of teachers and students, so as to form a systematic and perfect big data sharing platform, to ensure that college teachers, parents, and students themselves can understand the trends of students' thinking dynamics, behavioral preferences, values, and other trends through the sharing platform. Through rational use of the interactive transmission and sharing functions of multidirectional information, highlight the advantages of big data information management, form a comprehensive pattern of education, and constantly realize intelligent management.

(2) Enhance data awareness and improve processing efficiency. Information technology era, the vast amounts of data and information structure, and the information change speed have been accelerated, and with efficiency of college students management work, teachers need to strengthen the consciousness of the data; all relevant data should be brought into the scope of data collection, give prominence to the big data integration, and ensure the timeliness of data information. Make full use of big data processing technology, set up a professional big data management team, emphasize the compatibility of data between different databases, and ensure the dynamic budget of college students' ideological dynamics, behavioral preferences, and other accurateness, so as to realize the scientific warning of college students' study and behavior. Actively use the sharing of modern network technology, with the help of big data information collection and processing ability, to achieve the information collection, analysis, and prediction of all the students in colleges and universities, to summarize the common problems, and put forward effective management measures, and constantly improve the management efficiency of college students. 
(3) Colleges and universities should combine educational objectives and talent training mode effectively, emphasize the integrated management of data sources, and coordinate teaching system, behavior system, and early warning system. In order to ensure the effectiveness of college student management, colleges should pay attention to strengthening matrix construction and actively build authoritative institutions. In the process of daily life and learning management of college students, strengthen the management and punishment of college students, in strict accordance with the relevant provisions of the punishment of students who violate discipline, in order to fundamentally improve the importance of college students to the school management system, so that they can consciously manage and standardize their own behavior.

(4) Establish an early warning mechanism. The student administration departments of colleges and universities should strengthen the publicity and education and ensure that all teachers, students, and administrators can correctly understand big data technology. Attach importance to the introduction of high-quality data management personnel and ensure that they can extract sensitive data from the mass of data information. Strictly regulate the input operation of teachers and students' information and increase data education, in order to ensure the accuracy of background data processing and analysis and reduce the difficulty of data processing management teachers. Formulate data management plans and programs and optimization of firewall technology, determine the level of database information disclosure, clear different identities to view the level and authority settings, and do a good job of confidentiality provisions and agreement signing, to effectively protect the data security, to avoid the occurrence of network violence and infringement.

\section{Data Availability}

The data set can be accessed upon request.

\section{Conflicts of Interest}

The author declares that there are no conflicts of interest.

\section{References}

[1] J. Fan, "Research on individualized service of ideological and political education in universities in big data era," Journal of Changchun University, vol. 27, no. 6, pp. 47-50, 2017.

[2] T. A. Hart and M. Sharfman, "Assessing the concurrent validity of the revised kinder, lydenberg, and domini corporate social performance indicators," Business \& Society, vol. 54, no. 5, pp. 575-598, 2015.

[3] G. D. A. Pederzini, "Strategic management cultures: historical connections with science," Journal of Management History, vol. 22, no. 2, pp. 214-235, 2016.
[4] A. Amran, H. Fauzi, and Y. Purwanto, "Social responsibility disclosure in Islamic banks: a comparative study of Indonesia and Malaysia," Journal of Financial Reporting \& Accounting, vol. 15, no. 1, pp. 99-115, 2017.

[5] A. Lauder, R. F. Sari, and N. Suwartha, "Critical review of a global campus sustainability ranking: GreenMetric," Journal of Cleaner Production, vol. 108, pp. 852-863, 2015.

[6] F. U. Gómez, C. Sáez-Navarrete, S. R. Lioi, and V. I. Marzuca, "Adaptable model for assessing sustainability in higher education," Journal of Cleaner Production, vol. 107, pp. 475-485, 2015.

[7] J. Dlouhá, L. Henderson, and D. Kapitulčinová, "Sustainability-oriented higher education networks: characteristics and achievements in the context of the UN DESD," Journal of Cleaner Production, vol. 172, pp. 4263-4276, 2018.

[8] L. Liu, Y. S. Wang, and T. J. Wu, "Student satisfaction scale development and application for sport management in China," Eurasia Journal of Mathematics, Science and Technology Education, vol. 13, no. 5, pp. 1429-1444, 2017.

[9] I. N. Emelyanova, O. A. Teplyakova, and O. A. Teplyakova, "Mobility of Russian university students as a phenomenon and a management problem," University Management: Practice and Analysis, vol. 24, no. 2, pp. 131-144, 2020.

[10] M. Turner, C. Scott-Young, and S. Holdsworth, "Developing the resilient project professional: examining the student experience," International Journal of Managing Projects in Business, vol. 12, no. 3, pp. 716-729, 2019.

[11] K. H. Yang, "A study on the development of university student's learning competency scales," The Journal of Lifelong Education and HRD, vol. 12, no. 1, pp. 29-64, 2016.

[12] M. Jakubiak, M. Cholewa-Wiktor, and A. Sitko-Lutek, "Sustainable development and pro-ecological education in the opinion of students of management," in Proceedings of the 11th International Conference on Education and New Learning Technologies (EDULEARN), pp. 700-705, Palma de Mallorca, (Spain), July 2019.

[13] F. Y. Wei, "Research on the students' rights guarantee in the management of colleges and universities," in Proceedings of the International Conference on Innovations in Economic Management and Social Science (IEMSS), vol. 29, pp. 1582-1587, Hangzhou, China, April 2017.

[14] M. Chankseliani, "The politics of student mobility: links between outbound student flows and the democratic development of post-Soviet Eurasia," International Journal of Educational Development, vol. 62, pp. 281-288, 2018.

[15] R. Brooks, "Higher education mobilities: a cross-national European comparison," Geoforum, vol. 93, pp. 87-96, 2018.

[16] M. N. D. Tran, K. Moore, and M. C. Shone, "Interactive mobilities: conceptualising VFR tourism of international students," Journal of Hospitality and Tourism Management, vol. 35, pp. 85-91, 2018.

[17] A. Cuzzocrea and E. Damiani, "Making the pedigree to your big data repository: innovative methods, solutions, and algorithms for supporting big data privacy in distributed settings via data-driven paradigms," in Proceedings of the 43rd IEEE-Computer-Society Annual International Computers, Software and Applications Conference (COMPSAC), vol. 2, pp. 508-516, Milwaukee, WI, USA, July 2019.

[18] P. Senellart, "Provenance and probabilities in relational databases: from theory to practice," Sigmod Record, vol. 46, no. 4, pp. 5-15, 2017.

[19] S. Kumar, S. Madria, and M. Linderman, "M-Grid: a distributed framework for multidimensional indexing and 
querying of location based data," Distributed and Parallel Databases, vol. 35, no. 1, pp. 55-81, 2017.

[20] X. Yan, X. Feng, C. Song, and X. Hu, "Bidirectional feedback dynamic particle filter with big data for the particle degeneracy problem," Tsinghua Science and Technology, vol. 23, no. 4, pp. 463-478, 2018.

[21] L. Cai, X. W. Wang, J. N. Cao, K. Li, and C. Hui, "Adaptive caching strategy based on big data learning in ICN," Journal of Internet Technology, vol. 19, no. 6, pp. 1677-1689, 2018.

[22] S. Akter, M. A. Hossain, Q. Lu, and S. M. R. Shams, "Big datadriven strategic orientation in international marketing," International Marketing Review, vol. 38, no. 5, pp. 927-947, 2021.

[23] J. R. Huie, C. A. Almeida, and A. R. Ferguson, "Neurotrauma as a big-data problem," Current Opinion in Neurology, vol. 31, no. 6 , pp. 702-708, 2018

[24] J. Ding, V. Nathan, M. Alizadeh, and T. Kraska, "Tsunami: a learned multi-dimensional index for correlated data and skewed workloads," Proceedings of the Vldb Endowment, vol. 14, no. 2, pp. 74-86, 2020.

[25] J. Z. Qi, G. L. Liu, L. Kulik, and C. S. Jensen, "Effectively learning spatial indices," Proceedings of the Vldb Endowment, vol. 13, no. 11, pp. 2341-2354, 2020.

[26] P. Ferragina and G. Vinciguerra, "The PGM-index: a fully-dynamic compressed learned index with provable worstcase bounds," Proceedings of the Vldb Endowment, vol. 13, no. 8, pp. 1162-1175, 2020.

[27] T. Kraska, A. Beutel, N. Polyzotis, H. Chi, and J. Dean, "The case for learned index structures," in Proceedings of the 44th ACM SIGMOD International Conference on Management of Data, pp. 489-504, Houston TX USA, May 2018.

[28] L. Chen, Y. Gao, and X. Li, "Efficient metric indexing for similarity search and similarity joins," IEEE Transactions on Knowledge and Data Engineering, vol. 29, no. 3, pp. 556-571, 2017.

[29] J. Yu and M. Sarwat, "Two birds, one stone: a fast, yet lightweight, indexing scheme for modern database systems," Proceedings of the Vldb Endowment, vol. 10, no. 4, pp. 385-396, 2016. 